\title{
TURISMO E RECURSOS ENDÓGENOS COMO CATALIZADORES DO DESENVOLVIMENTO LOCAL SUSTENTÁVEL NOS TERRITÓRIOS DE BAIXA DENSIDADE POPULACIONAL
}

Data de aceite: 01/12/2020

Data de submissão: 06/10/2020

Nuno Manuel dos Santos Carvalho

Escola Superior de Educação - Insituto

Politécnico de Coimbra

CICS.NOVA - Centro Interdisciplinar de

Ciências Socais - FCSH

Universidade Nova de Lisboa

Coimbra - Portugal

https://orcid.org/0000-0002-0970-7331

RESUMO: Consequência de políticas centralistas baseadas num modelo de desenvolvimento centrado no paradigma funcionalista, vastas regiões do interior de Portugal Continental sofreram ao longo de décadas um forte declínio demográfico, económico e social. O presente texto, sob a forma de ensaio, reflete sobre a importância da conservação e valorização dos património(s) destes territórios de baixa densidade populacional enquanto recursos endógenos para o desenvolvimento local sustentável através da promoção do turismo no sentido da inversão deste ciclo de declínio.

PALAVRAS-CHAVE: Turismo, paradigmas funcionalista e territorialista, territórios, recursos endógenos, desenvolvimento local sustentável.

\section{TOURISM AND ENDOGENOUS RESOURCES AS CATALYSTS FOR SUSTAINABLE LOCAL DEVELOPMENT IN LOW POPULATION DENSITY TERRITORIES}

ABSTRACT: Result of centralist policies based on a development model focused on the functionalist paradigm, vast regions of the interior of Mainland Portugal have suffered for decades a strong demographic, economic and social decline. This essay text reflects on the importance of conservation and enhancement of the heritage

(s) of these low population density territories as endogenous resources for sustainable local development through the promotion of tourism towards the reversal of this cycle of decline.

KEYWORDS: Tourism, functionalist and territorialist paradigms, territories, endogenous resources, sustainable local development.

\section{1। DA CRISE DO VELHO PARADIGMA, À EMERGÊNCIA DE UM NOVO PARADIGMA}

Em Portugal, a visão funcionalista do desenvolvimento foi, a perspetiva política e económica dominante, com consequências desastrosas para o país das quais se destacam a litoralização das atividades económicas, nomeadamente a sua concentração nas áreas de Lisboa e Porto, a desvitalização de vastas regiões do interior do país, onde o problema demográfico as afeta de modo muito preocupante. AMARO (1990 cit p/ MERGULHÃO 1997), considera que em virtude de se terem vindo a adotar constantemente 
em Portugal políticas de desenvolvimento baseadas em interesses nacionais e em que os interesses regionais foram subalternizados de uma forma arbitrária e pouco criteriosa levou à existência de um país com duas realidades distintas.

Portugal regista, assim, fortes assimetrias regionais entre o litoral e o interior muito preocupantes, conforme o atesta o Plano Nacional de Coesão Territorial (PNCT) apresentado pelo governo em outubro de 2016, no qual pode ler-se, no texto introdutório, escrito pela coordenadora da unidade de missão, Helena Freitas: "assistimos a uma litoralização progressiva do país, acentuando-se a tendência para o despovoamento, envelhecimento e empobrecimento das regiões do interior as quais representam cerca de $2 / 3$ do território nacional. A perda de coesão territorial tem vindo a agravar-se, e convoca-nos para a procura urgente de soluções que contrariem uma trajetória insustentável" (UMVI, 2016 p. 3).

O paradigma funcionalista, assenta: no crescimento económico; tem um caráter exógeno; é um desenvolvimento de cima para baixo (top-down); alicerçase em determinados sectores da atividade económica, em áreas geográficas bem específicas; é monolítico e centralizado; não atende à satisfação das necessidades básicas das populações; não mobiliza nem estimula a participação.

O falhanço deste modelo de desenvolvimento assente no paradigma funcionalista, remete para novos conceitos de desenvolvimento entre os quais o de desenvolvimento local, que radica num novo paradigma, o paradigma territorialista.

Neste sentido, associado ao paradigma territorialista, emerge, como alternativa ao modelo clássico de desenvolvimento, o conceito de desenvolvimento local que, segundo Amaro é um processo de transformação e de mudança, "é o desenvolvimento a partir das regiões, das comunidades e dos grupos mais desfavorecidos" (AMARO, 2001, p. 162). O termo local contextualiza-se dentro do espaço físico no qual os indivíduos se relacionam e gerem os recursos aí existentes e não com as definições geográficas ou autárquicas. Segundo Reis, "representa as linhas finas dos contextos de vida e de sociabilidade do homem" (REIS, 1994, p. 3).A participação dos cidadãos e restantes atores revela-se, assim, como condição para o sucesso das políticas definidas pelo novo paradigma.

\footnotetext{
"a perspetiva territorialista veio colmatar uma grande lacuna do paradigma anterior ao conferir aos atores locais o desempenho de um papel fundamental nas estratégias de desenvolvimento, nomeadamente ao incentivar e motivar desde o seu início a participação das populações implicadas, quer através das propostas de acção, quer através da definição de objetivos a alcançar, tornando, dessa forma, as populações "cúmplices" das iniciativas levadas a efeito e aumentando em consequência as possibilidades de sucesso". (Mergulhão, 1997, p. 148-149)
}

Temos assim, que, numa perspetiva territorialista, o desenvolvimento vai 
para além do crescimento económico, alargando os seus horizontes para o nível social, ambiental e político, em que a especificidade de cada região, de cada sociedade, é tida em conta. Os recursos endógenos, e as características de cada comunidade são valorizadas e são as comunidades locais que vão constituir a base do processo de desenvolvimento. A comunidade é envolvida e levada a participar ativamente nesse desenvolvimento, contribuindo assim para a própria melhoria das suas condições de vida.

É, pois, nesta perspetiva integradora, assente numa base territorial e que incorpora os pilares do designado desenvolvimento sustentável tal como hoje são concebidos: económico, ambiental, social e político/institucional que enquadramos o desenvolvimento local numa perspetiva de sustentabilidade.

Assim, o desenvolvimento local está associado, normalmente, a iniciativas inovadoras e mobilizadoras da coletividade, articulando as potencialidades locais com as condições dadas pelo contexto. É um processo endógenogeralmente assente em pequenas unidades territoriais e agrupamentos humanos capaz de promover o dinamismo económico e a melhoria da qualidade de vida das populações. Representa uma singular transformação nas bases económicas e na organização social ao nível local, resultante da mobilização das energias da sociedade, explorando as suas capacidades e potencialidades específicas. Para ser um processo consistente e sustentável, o desenvolvimento deve aumentar as oportunidades sociais e a viabilidade e competitividade da economia local, aumentando os rendimentos e as formas de riqueza ao mesmo tempo que assegura a conservação dos recursos naturais (CARVALHO, 2009).

O desenvolvimento local sustentável incorpora as dimensões da sustentabilidade, subjacentes ao conceito de desenvolvimento sustentável (económica, ambiental, social e política/institucional) e procura fomentar o desenvolvimento de unidades sócio-territoriais, que são delimitadas por um conjunto de práticas de diagnóstico e planeamento participativo, partindo das potencialidades desse território. Acaba assim, por ser um espaço onde são postas em ação práticas de carácter político, social e de desenvolvimento, tendo por base a sustentabilidade enquanto elo de ligação destas práticas. Deverá promover a potenciação do impacte das ações, tanto governamentais como não-governamentais, por forma a investir na melhoria das condições de vida das populações. É possível atingir este estado de qualidade através do investimento na dinamização de potenciais recursos endógenos, do desencadeamento de ações cidadãs e voluntárias e do estabelecimento de parcerias. O desenvolvimento local sustentável deverá, também, fazer uso dos programas exógenos potenciando, assim, as iniciativas endógenas, que provêm das sinergias estabelecidas pelos atores da comunidade (CARVALHO, 2009). 
O desenvolvimento local sustentável, constitui, assim, uma fonte de esperança para todas as regiões do interior do país que, continuam a sofrer o preocupante processo de despovoamento.

\section{I TURISMO E RECURSOS ENDÓGENOS COMO CATALIZADORES DO DESENVOLVIMENTO LOCAL SUSTENTÁVEL}

Assim, o turismo constitui uma forma de aproveitamento dos recursos próprios do território, assumindo-se como uma das atividades que melhor pode aproveitar os recursos endógenos dos territórios e constituir-se num importante fator de desenvolvimento dependendo das especificidades de cada região e da maior ou menor relevância que lhe é atribuída.

É, pois, no sentido de contrariar e reverter os cenários patentes nos territórios de baixa densidade populacional que urge implementar políticas de desenvolvimento local sustentável, baseadas nos recursos endógenos com destaque para os recursos patrimoniais e dentro destes os recursos naturais, particularmente nas regiões com áreas classificadas, quer integrando a Rede Nacional de Áreas Protegidas, quer a Rede Natura 2000, pois estes territórios classificados são áreas de excelência, do ponto de vista cultural, natural e paisagístico de grande relevância para o turismo cultural e o turismo de natureza.

O que cada região tem de característico e a diferencia das outras regiões é fundamental, é insubstituível para o seu próprio desenvolvimento, sendo de realçar "a necessidade de aproveitar as diversidades locais e regionais e as vantagens específicas de produtos tradicionais de elevada qualidade" ( CRISTÓVÃO e TIBÉRIO, 1993, cit p/ RITA e MERGULHÃO, 1997, p. 37.

Efetivamente, é a diversidade do património, natural e cultual que diferencia os territórios e que pode ter efeitos positivos a dois níveis, desde que devidamente trabalhados: por um lado, o seu caráter diferenciador permite que os territórios se afirmem pela sua singularidade, fazendo face a mecanismos e processos de globalização uniformizadores, e, por outro lado, ao invés de serem "concorrentes" dos territórios vizinhos, potenciam sinergias com estes, também eles portadores de singularidade, alargando, assim, a base da oferta, com efeitos benéficos para todos, e elevando o desenvolvimento a uma escala regional. Para tal serão de evitar bairrismos incompreensíveis que, por vezes, ainda se observam.

É, neste sentido que as estratégias de desenvolvimento local dos territórios de baixa densidade podem fazer do turismo um dos principais setores para o desenvolvimento desses territórios, na medida em que potencia a valorização e a preservação dos seus recursos endógenos, contribuindo, assim, para o desenvolvimento económico, ambiental e social, particularmente através da criação 
de emprego nas diversas áreas de atividade. Um turismo sustentável que respeite, preserve e promova os valores locais e seja capaz de catalisar sinergias entre os diversos territórios vizinhos no sentido de potenciar os recursos de cada um de uma forma integrada e complementar.

Em termos de mecanismos de financiamento entendemos que estão criadas condições através do programa PRODER - Programa de Desenvolvimento Rural e, sobretudo, o programa PROVERE - Programa de Valorização Económica dos Recursos Endógenos, no âmbito do quadro comunitário de apoio, Portugal 2020, constituírem-se como importantes instrumentos para implementação de verdadeiros projetos de desenvolvimento local. O programa PROVERE, está vocacionado, conforme patente na sua designação, para a valorização económica dos recursos endógenos, particularmente os recursos distintivos que apresentam capital simbólico, nos territórios de baixa densidade.

De notar a importância que, no âmbito dos quadros comunitários de apoio, - vêm do QREN e mantêm-se no PT 2020 - assumem a criação das designadas DLBC - Desenvolvimento Local de Base Comunitária, na medida em que permitem a congregação de sinergias dos atores locais.

\footnotetext{
"O Desenvolvimento Local de Base Comunitária (DLBC) é uma abordagem territorial, através da qual são implementadas Estratégias de Desenvolvimento Local (EDL) concebidas por Grupos de Ação Local (GAL) com uma estreita ligação ao tecido social, económico e institucional de cada território, visando o desenvolvimento, diversificação e competitividade da economia e a melhoria das condições de vida das populações, (...) promovendo em territórios específicos o desenvolvimento local."(MAOTDR, 2014, p.385).
}

Contudo, para que tal seja possível é necessária a adoção dum novo modelo de planeamento que exige a aceitação duma nova cultura política, implicando uma mudança das relações sociais, de valores e uma reforma na consciência da cidadania, capaz de mobilizar todos os atores do território. Ou seja, o planeamento levado a cabo, segundo uma ótica de desenvolvimento local sustentável, deverá ser democrático, permitindo que os cidadãos tenham um papel relevante no processo de desenvolvimento da sociedade.

Segundo (CARVALHO, 2009) a Agenda 21 Local constitui-se como o instrumento de planeamento estratégico privilegiado para a implementação do desenvolvimento local sustentável nesta regiões, quer a nível municipal, através das Câmaras Municipais, quer a nível intermunicipal, através da construção e implementação de Agendas 21 Local regionais através das Comunidades Intermunicipais (CIM), cabendo, assim, um papel determinante às instituições de poder local, no combate ao velho paradigma funcionalista, em prol do desenvolvimento dos seus territórios. 
A preservação e valorização dos recursos endógenos passa, pois, por processos de planeamento estratégico locais que façam os diagnósticos de potencialidades e necessidades corretos e que promovam projetos de desenvolvimento assentes em processos de parceria alargados que envolvam todos os atores, públicos e privados, aproveitando os mecanismos de financiamento disponíveis.

Assim, o processo de planeamento da sociedade local sustentável não se constrói só sobre bases técnicas, racionais, lógicas, materiais e quantitativas, mas necessita de técnicas pedagógicas participativas no processo de planeamento democrático e para tal é necessário criar metodologias interativas de elaboração de planos municipais. Segundo esta ótica se o planeamento for participativo poderá ser entendido como um processo de aprendizagem e conquista, mexendo com a estrutura de poder e cultura política.

Para concluir, afirmamos que as escolhas políticas futuras são determinantes, para as regiões de baixa densidade e têm "apenas" duas opções possíveis: uma, é a promoção de políticas de desenvolvimento local sustentável, assentes nos recursos endógenos, como fator de diferenciação, resgatando estes territórios de décadas de abandono e promovendo a sua coesão territorial e consequente sustentabilidade revitalizando-os, quer melhorando a qualidade de vida das suas populações, quer atraindo população jovem e qualificada no sentido de inverter o envelhecimento demográfico; a outra, é teimar na visão do velho paradigma funcionalista, supostamente a pensar nos interesses nacionais, esquecendo-se que estas regiões também são parte integrante do país, continuando, assim, a agravar o despovoamento, o envelhecimento e o empobrecimento destas regiões.

\section{REFERÊNCIAS}

AMARO, R. R. O Conceito de Desenvolvimento Local no Quadro da Revisão do Conceito de Desenvolvimento. In: DESENVOLVER (DES)ENVOLVENDO - REFLEXÕES E PISTAS PARA O DESENVOLVIMENTO LOCAL. Atas, Messejana: ESDIME, 2001. p. 155-169.

CARVALHO, N. Desenvolvimento local sustentável. A agenda 21 local como instrumento de política privilegiado para a sua implementação. Barlia - Revista científica sobre ambiente e desenvolvimento, Leira, n. 5, p. 79-94, 2009.

MAOTDR - Ministério do Ambiente Ordenamento do Território e Desenvolvimento Regional. PROVERE - Programa de Valorização Económica dos Recursos Endógenos. Lisboa: MAOTDR, 2008.

MAOTDR - Ministério do Ambiente Ordenamento do Território e Desenvolvimento Regional. Portugal 2020: 2014-2020. Lisboa: MAOTDR, 2014. 
MERGULHÃO, L. Desenvolvimento e ruralidade: alguns aspectos sociológicos. Economia e Sociologia, Évora, n. 64, p. 143-156, 1997.

REIS, J. Território e sistemas produtivos locais: uma reflexão sobre as economias locais. Revista Crítica das Ciências Sociais, Coimbra, n. 25/26, p.127-141, 1988.

REIS, J. O desenvolvimento local é possível? Lisboa: Sociedade Portuguesa de Estudos Rurais, 1994

UMVI - Unidade de Missão para a Valorização do Interior. Programa Nacional para a Coesão Territorial. Lisboa: MAOTDR, 2016. 